\title{
Drug repurposing commonly against Dengue Virus capsid and SARS-CoV-2 nucleocapsid: \\ An in silico approach
}

Debica Mukherjee ${ }^{1,2}$, Rupesh Kumar ${ }^{3}$, Upasana Ray*1,2

${ }^{1}$ CSIR-Indian Institute of Chemical Biology, 4, Raja S.C., Mullick Road, Jadavpur, Kolkata700032, West Bengal, India.

${ }^{2}$ Academy of Scientific and Innovative Research (AcSIR), Ghaziabad- 201002, India

${ }^{3}$ Memorial Sloan Kettering Cancer Center, 1275 York Ave., New York, NY 10065

${ }^{*}$ Correspondence: ray.upasana@gmail.com

upasana.ray@iicb.res.in

Key words: Dengue virus, SARS-CoV-2, nucleocapsid, capsid, assembly, drug repurposing

\begin{abstract}
:
In the middle of SARS-CoV-2 pandemic, dengue virus (DENV) is giving a silent warning as the season approaches nearer. There is no specific antiviral against DENV for use in the clinics. Thus, considering these facts we can potentially face both these viruses together increasing the clinical burden. The search for anti-viral drugs against SARS-CoV-2 is in full swing and repurposing of already 'in-use' drugs against other diseases or COVID-19 has drawn significant attention. Earlier we had reported few FDA approved anti-viral and anti-microbial drugs that could be tested for binding with SARS-CoV-2 nucleocapsid $N$ terminal domain. We explored the possibility of interactions of the drugs screened for SARS-CoV2 with Dengue virus capsid protein. We report five FDA approved drugs that were seen to be docking onto the SARS-CoV2 nucleocapsid RNA binding domain, also docking well with DENV capsid protein on the RNA binding site and/or the capsid's membrane fusion domain. Thus, the present study proposes these five drugs as common antiviral candidates against both SARS-CoV-2 and DENV although the in silico study is subject to further validations.
\end{abstract}

\section{Introduction:}

In the tropical and sub-tropical countries, Dengue virus (DENV) remains a constant threat to human life. According to the world health organisation (WHO), every year 100-400 million cases of dengue virus infections are reported all over the world (1).

Capsid protein, one of the structural proteins of DENV plays a key role in the virus assembly by packaging the viral RNA to form mature virion particle. This $12 \mathrm{KDa}$ protein is rich in basic and hydrophobic amino acids which ensures its role in RNA binding and membrane fusion. The protein forms a homodimer conformation with each monomer consisting of four alpha helical chains ( $\alpha 1-\alpha 4)$ (Figure 1 ) and the $N$ - terminal unstructured region (2). Helix $\alpha 1-\alpha 3$ forms the hydrophobic core of the protein and the longest helix $\alpha 4$ extends out of the core to interact with the negatively charged viral RNA (2). The $\alpha 1$ and $\alpha 2$ helices are mostly composed of uncharged hydrophobic residues with a conserved membrane fusion domain in $\alpha 2$ helix which creates the lipid membrane binding pocket $(3,4)$. On the other hand, interaction of $\alpha 4-\alpha 4^{\prime}$ helix enables nucleic acid binding and stabilise the nucleocapsid core formation (5). 
Apart from RNA packaging, the DENV capsid also induces FAS-dependent apoptosis and regulate transcription by binding with histones $(6,7)$.

Repurposing of clinically approved drugs against the multifunctional capsid protein could be beneficial for treatment/ management of severities of DENV infection. We reported previously that some of the FDA (food and drug administration US) approved antiviral and anti-microbial drugs dock strongly with RNA binding region of SARS-CoV2 nucleocapsid protein and thus might interfere with nucleocapsid-RNA interaction (8). Here, we screened interaction properties of the same shortlisted drugs (Table 1) with DENV capsid protein to

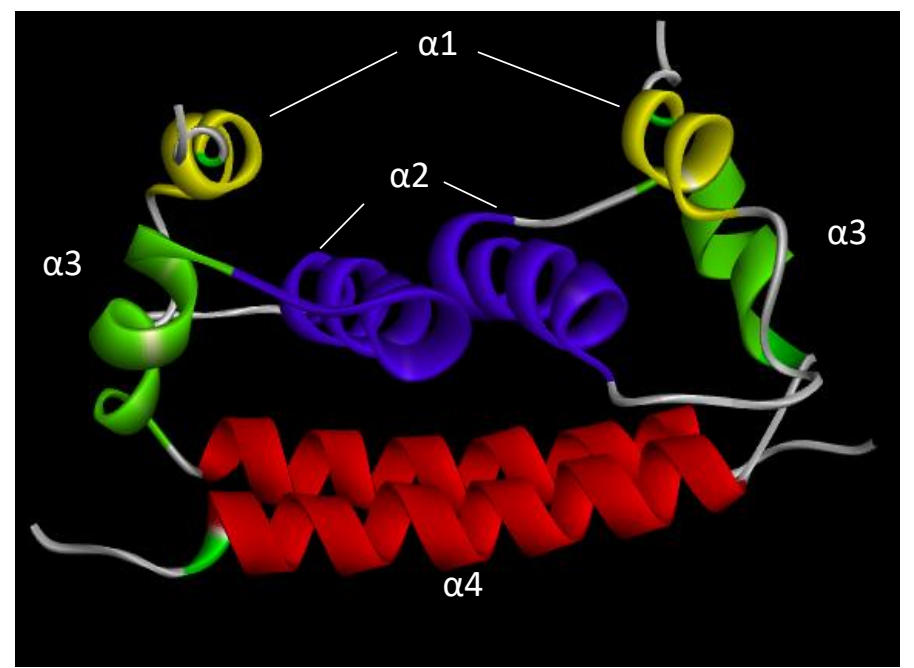

Figure1: Dimeric structure of DENV- capsid protein, helix $\alpha 1$ is yellow, $\alpha 2$ is blue, $\alpha 3$ is green and $\alpha 4$ is red

investigate the possibility of identification of common drug candidate/s that can be used to target both the viruses. This was a blind drug exploration.

\section{Table 1: Mode of action of shortlisted drugs}

\begin{tabular}{|l|l|l|l|}
\hline $\begin{array}{l}\text { Nature of } \\
\text { drug }\end{array}$ & Drug name & Mechanism of action & $\begin{array}{l}\text { Drug } \\
\text { bank ID }\end{array}$ \\
\hline Anti-viral & Daclatasvir & $\begin{array}{l}\text { Daclatasvir acts against hepatitis C } \\
\text { virus by inhibiting D1 domain of NS5A }\end{array}$ & DB09102 \\
\hline Anti-viral & Rilpavirine & $\begin{array}{l}\text { Rilpavirine binds to reverse } \\
\text { transcriptase (RT) enzyme of HIV-1 and } \\
\text { inhibits replication }\end{array}$ & DB008864 \\
\hline Anti-viral & Tipranavir & $\begin{array}{l}\text { Tipranavir binds to HIV-1 protease and } \\
\text { inhibit polyprotein processing }\end{array}$ & DB00932 \\
\hline Anti-viral & Etravirine & $\begin{array}{l}\text { Etravirine acts against reverse } \\
\text { transcriptase (RT) enzyme of HIV-1 }\end{array}$ & DB06414 \\
\hline Antimicrobial & Praziquantel & $\begin{array}{l}\text { Praziquantel influence worms' muscle } \\
\text { contraction by Ca2+ influx }\end{array}$ & DB01058 \\
\hline Antimicrobial & Rifampicine & $\begin{array}{l}\text { Rifampicine targets bacterial DNA } \\
\text { dependent RNA polymerase and } \\
\text { inhibit function mRNA synthesis }\end{array}$ & DB01045 \\
\hline
\end{tabular}




\section{Methods:}

A set of fourteen FDA approved anti-viral and anti-microbial drugs based on our earlier study (8) were screened to identify potential antiviral candidate/s against DENV capsid protein function.

The three-dimensional crystal structure of Dengue virus capsid protein (PDB ID: 1R6R) was downloaded from Protein Data Bank (PBD) (9). The protein was converted to a readable file format (.pdbqt) using AutoDock Tools $1.5 .6(10)$, after removing the solvent molecules and Tools 1.5.6 (10). protonated with polar hydrogens.

The 3D conformation of the drug molecules were retrieved from Pubchem in SDF format and then exported to PDB file by Pymol software followed by convertion to a supported format (.pdbqt) by AutoDock Tools 1.5.6.

All the drug compounds were virtually screened against DENV capsid protein using AutoDock vina (12). A blind docking was performed keeping the grid centre set at $X=2.041, Y=-7.998$, $Z=1.282$ and grid-box dimensions at $88 \AA$ X $62 \AA$ X $62 \AA$ with the exhaustiveness value 8 .

Among all the ligands top few drugs were selected for further analysis using Discovery Studio Visualizer v20.1.0.19295 (13) and PyMol software (14).

\section{Results and discussion:}

Total fourteen anti-viral and anti-microbial drugs were screened against DENV capsid. Drugs shortlisted for further analyses were Daclatasvir, Rilpivirin and Tipranavir among the anrivirals and Praziquantel and Rifampicing among the antimicrobials. Binding affinities and the interacting residues of the shortlisted all drugs are summarized in Table 2. The common residue of Dengue virus capsid interacting with all the three shortlisted antiviral drugs is lle 94.

Daclatasvir acts on non-structural protein 5A of Hepatitis C virus by interrupting its hyperphosphorylation (15). Among the screened anti-viral drugs Daclatasvir showed the highest binding affinity that is $-7.9 \mathrm{kcal} / \mathrm{mol}$ with dengue capsid protein. The key interacting residues of dengue virus capsid protein with Daclatasvir are Asn 93 (A), $\operatorname{Arg} 98(A)$ by conventional hydrogen bonds and Gly 70 (B), Arg 90 (A), Arg 97 (A) by other non-covalent interactions (Figure 2). Arg 93, Arg 98, Arg 90 and Arg 97 are the residues located within alpha helix $4(\alpha 4)$ and are involved in the formation of hydrophobic $\alpha 4-\alpha 4^{\prime}$ interface. These basic amino acids interact with viral RNA and help in RNA encapsulation to form mature virion. Thus, Daclatasvir binding might lead to competitive inhibition of RNA binding to Dengue virus capsid and in turn lead to disruption of efficient RNA encapsidation.

Rilpivirin is a non-nucleoside reverse transcriptase inhibitor (NNRTI) used against human immunodeficiency virus 1 (HIV1) (9). Rilpivirin was found to interact with the conserved membrane fusion residues Arg 55, Pro 61 and leu 66 within alpha helix 2 ( $\alpha 2$ ) and few residues (Ile94 and Gly 70) from alpha helix 4 (a4). However, this ligand does not form any conventional hydrogen bonds in its best docked conformation but the complex structure is stabilized by Pi-sigma, Pi-alkyl and Carbon-hydrogen bonds (Figure 3). These interactions 
might inhibit the protein to get in close contact with lipid membrane which is an essential step to assemble virus particle.

Tipranavir is a protease inhibitor that blocks polyprotein processing of human immunodeficiency virus (HIV1). By virtual screening it was predicted that this drug could bind to $\alpha 4$ interface of dengue capsid protein (Figure 4) and interact with few residues of membrane binding domain. Arg 97 and Arg 90 from alpha helix 4 (a4) participated in conventional hydrogen bonding and Ile 59, Pro 61 and Arg 55 from alpha helix 2 ( $\alpha 2$ ) formed Pi-alkyl bonds. This might result in inhibition of membrane fusion.

Among the antimicrobial drugs screened only Praziquantel bound with the capsid with a binding affinity less than $-7.0 \mathrm{kcal} / \mathrm{mol}$. Praziquantel is an anti-parasitic drug which cause severe muscular contraction in worm muscle cells. The best docked structure was stabilized by Pi-sigma, Pi-alkyl bonds with residues of $\alpha 2$ and $\alpha 4$ helices (Figure 5). Similar to Rilpivirin, Praziquantel might block capsid membrane fusion by interaction with hydrophobic residues (Pro 61, Arg 55 and Leu 66) of $\alpha 2$ chain required for membrane binding.

Rifampicin is widely used as anti-bacterial against several strains of Mycobacterium by forming a stable complex with DNA-dependent RNA polymerase. In-silico docking with Dengue virus capsid showed a binding affinity of $-6.9 \mathrm{kcal} / \mathrm{mol}$. Although this affinity was higher than the cut off value, we considered this drug for future studies as the interaction involved four hydrogen bonds. Rifampicin interacted with the residues of alpha helix 2 (Lys 45, Arg 55 and Ile 59) and alpha helix 4 (Glu 87) of the capsid protein (Figure 6). The residues within membrane fusion domain are the key interacting partners of rifampicin.

All the shortlisted drugs will further be validated at various levels. 


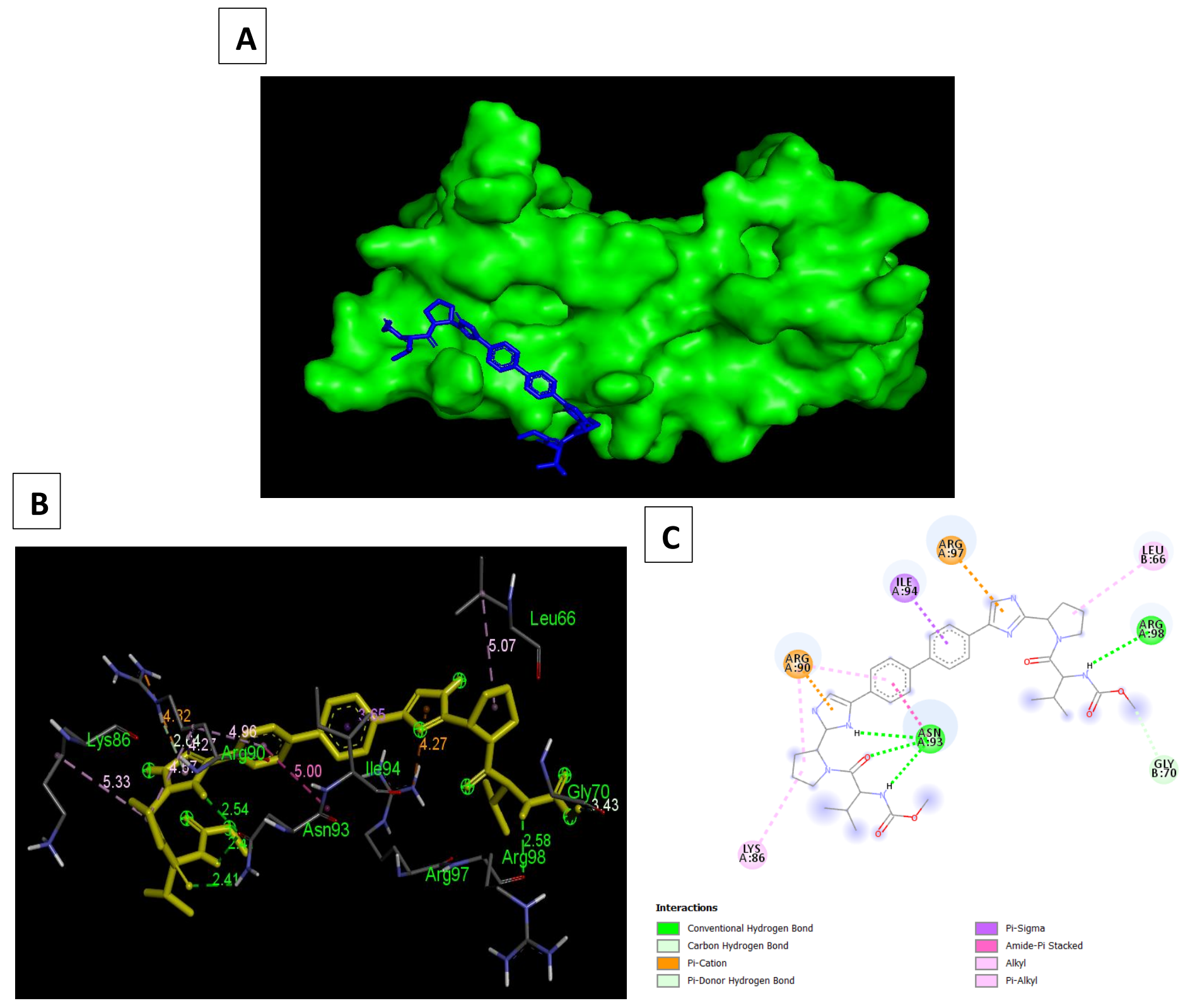

Figure 2: DENV capsid protein docked with anti-viral drug Daclatasvir. A. The best fitted pose of the ligand (blue) in the three-dimensional binding cavity of protein. B. Amino acid residues interacting with the ligand (yellow), bond lengths are indicated. $C$. The two-dimensional interaction map of the ligand. 


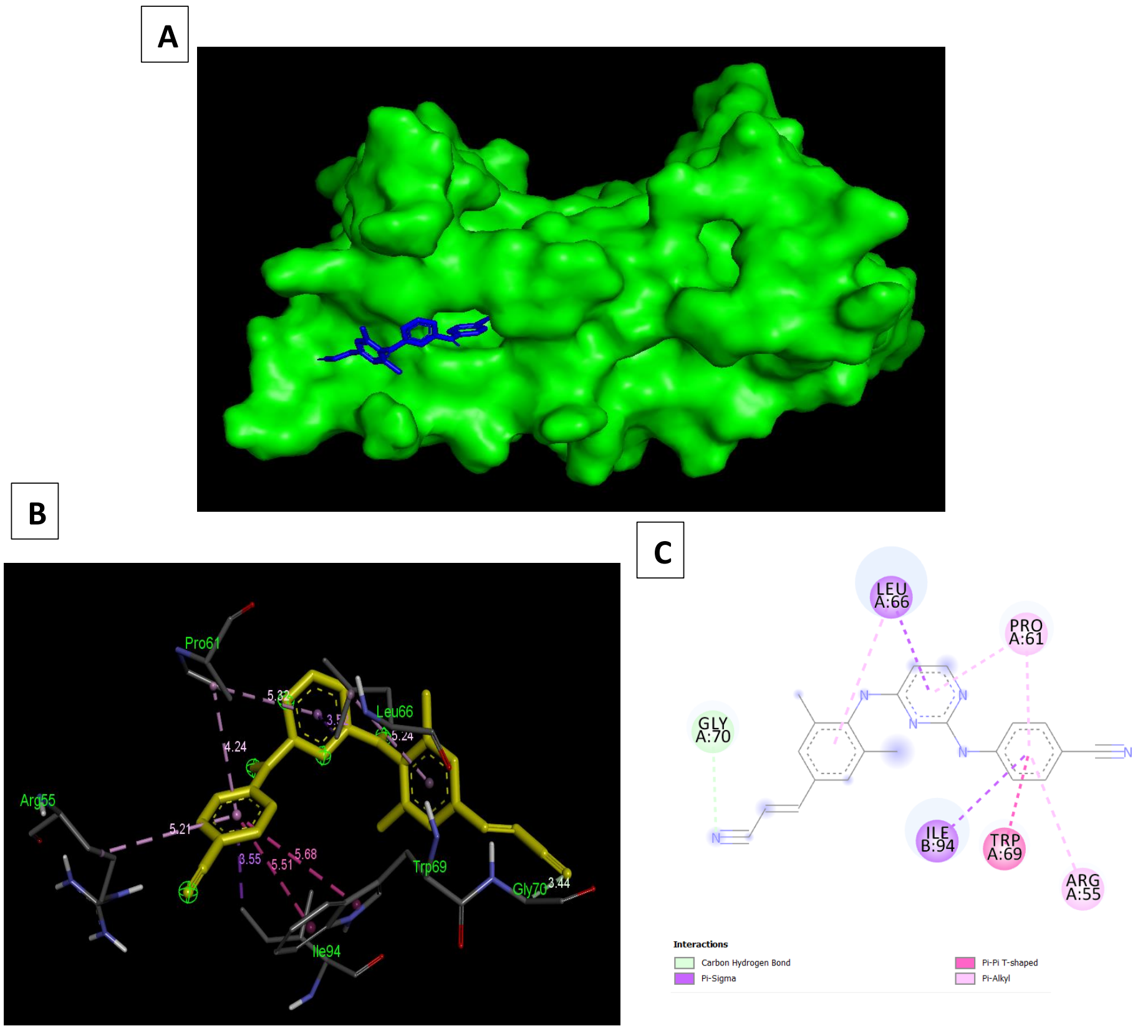

Figure 3: DENV capsid protein docked with anti-viral drug Rilpivirin. A. The best fitted pose of the ligand (blue) in the three-dimensional binding cavity of protein. B. Amino acid residues interacting with the ligand (yellow), bond lengths are indicated. $C$. The two-dimensional interaction map of the ligand. 
A

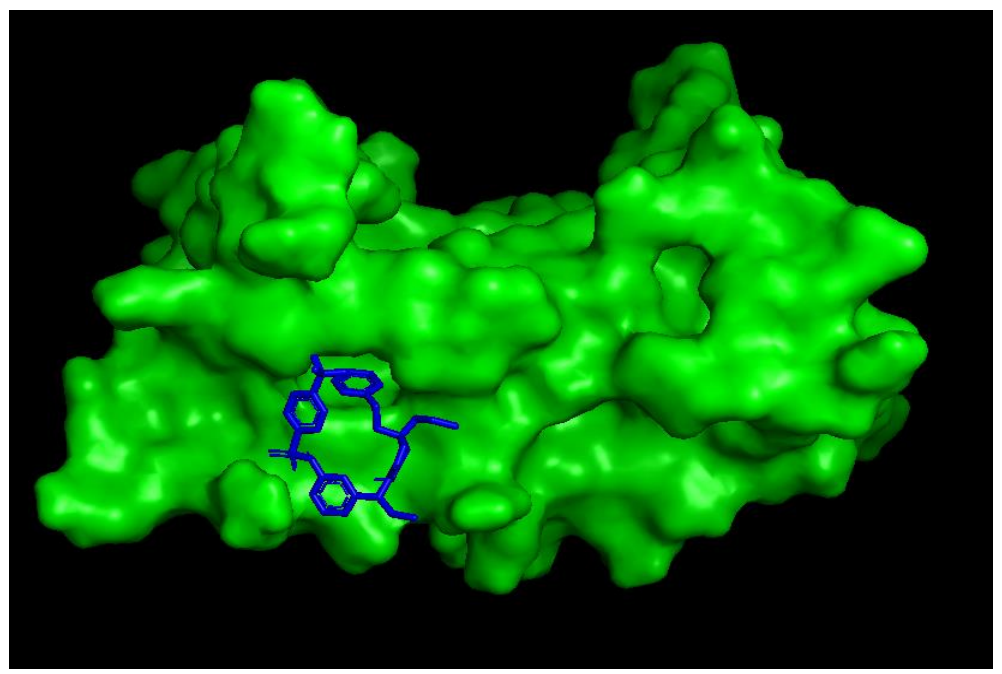

B

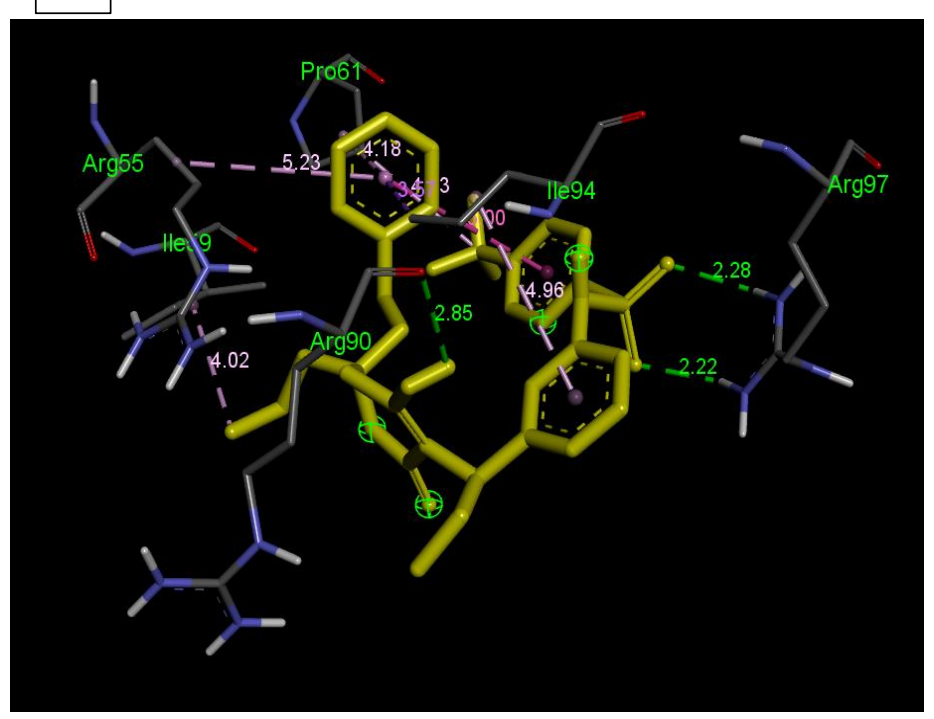

C

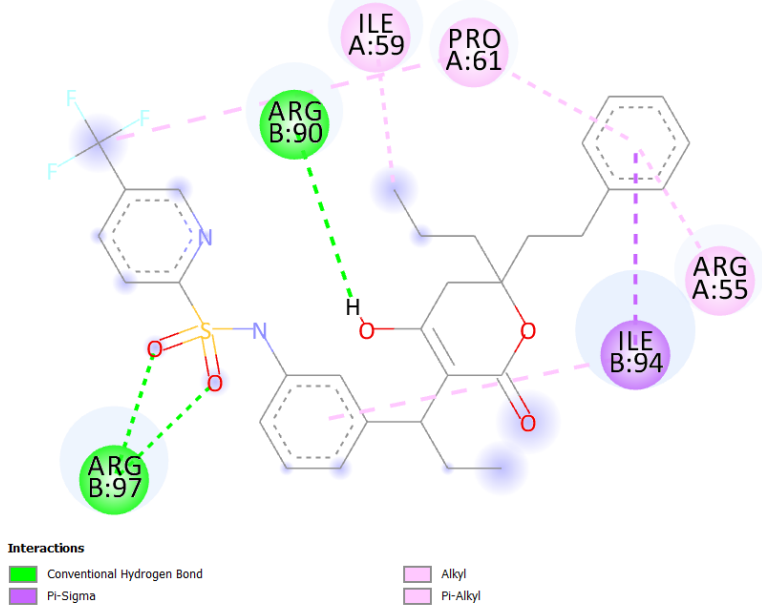

Figure 4: DENV capsid protein docked with anti-viral drug Tipranavir. A. The best fitted pose of the ligand (blue) in the three-dimensional binding cavity of protein. B. Amino acid residues interacting with the ligand (yellow), bond lengths are indicated. C. The two-dimensional interaction map of the ligand. 


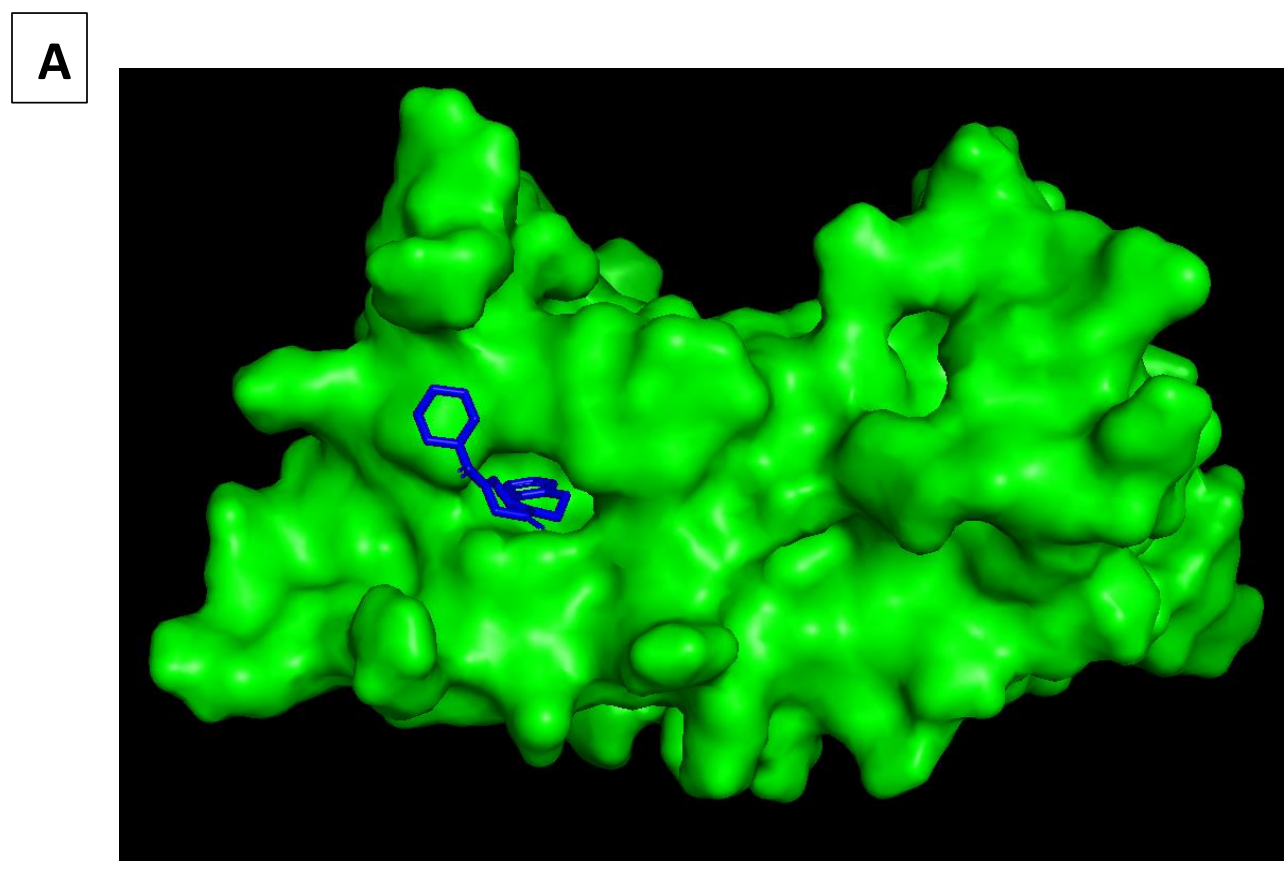

B
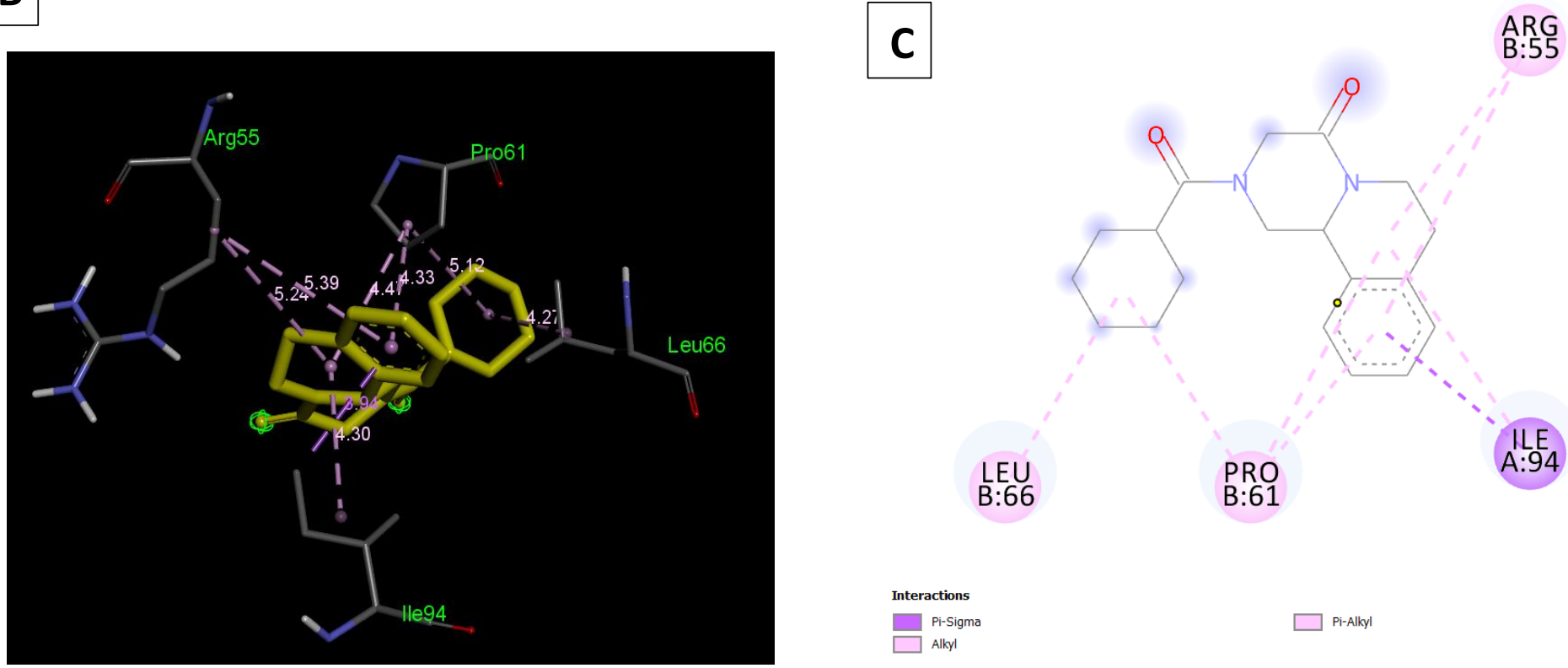

Interactions

Pi-Sigma

$\square$ Alkyl

Figure 5: DENV capsid protein docked with anti-viral drug Praziquantel. A. The best fitted pose of the ligand (blue) in the three-dimensional binding cavity of protein. B. Amino acid residues interacting with the ligand (yellow), bond lengths are indicated. $C$. The two-dimensional interaction map of the ligand. 


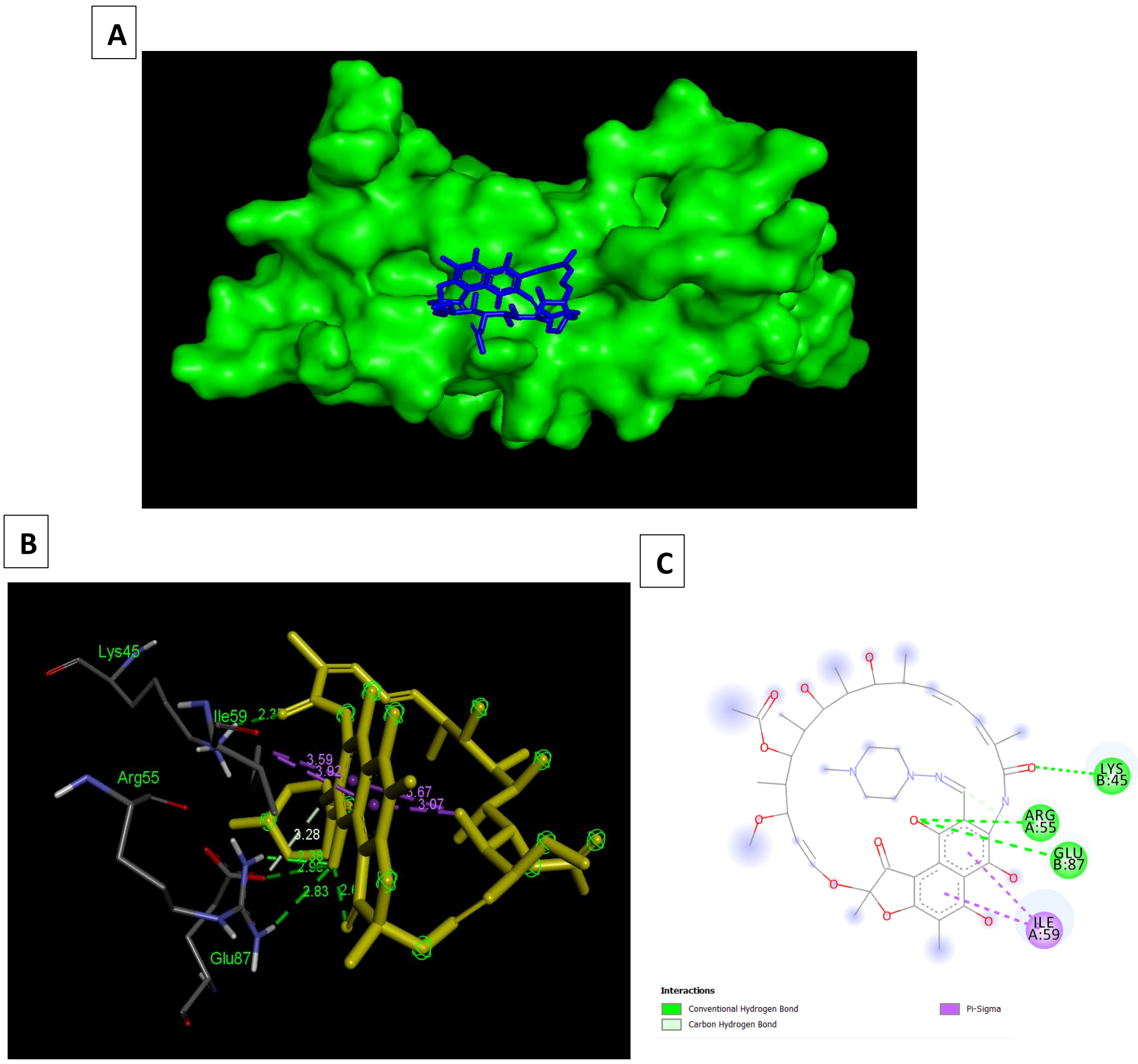

Figure 6: DENV capsid protein docked with anti-viral drug Rifampicin. A. The best fitted pose of the ligand (blue) in the three-dimensional binding cavity of protein. B. Amino acid residues interacting with the ligand (yellow), bond lengths are indicated. C. The two-dimensional interaction map of the ligand. 


\section{Summary:}

Capsid protein is around 80\% conserved among all four DENV serotypes (18) hence it might be a strong target for anti-viral drugs. The present study shed light on potential drug candidates for repurposing against Dengue virus capsid assembly and membrane fusion pror to exit. These drugs were previously reported as potential inhibitors of SARS-CoV-2 nucleocapsid-RNA interaction. The drug candidates have been predicted to have potential role in intervening with DENV capsid protein membrane integration and viral-RNA packaging which in turn might affect mature virion particle formation (Figure 7). However, ligands are complex chemical structures with several reactive atoms, so the chance of creating bonds is significantly high. Hence, to extend this study and further confirm, we will perform molecular dynamics studies. The inhibitory properties of suggested drugs need validations using in-vitro and ex-vivo assays.

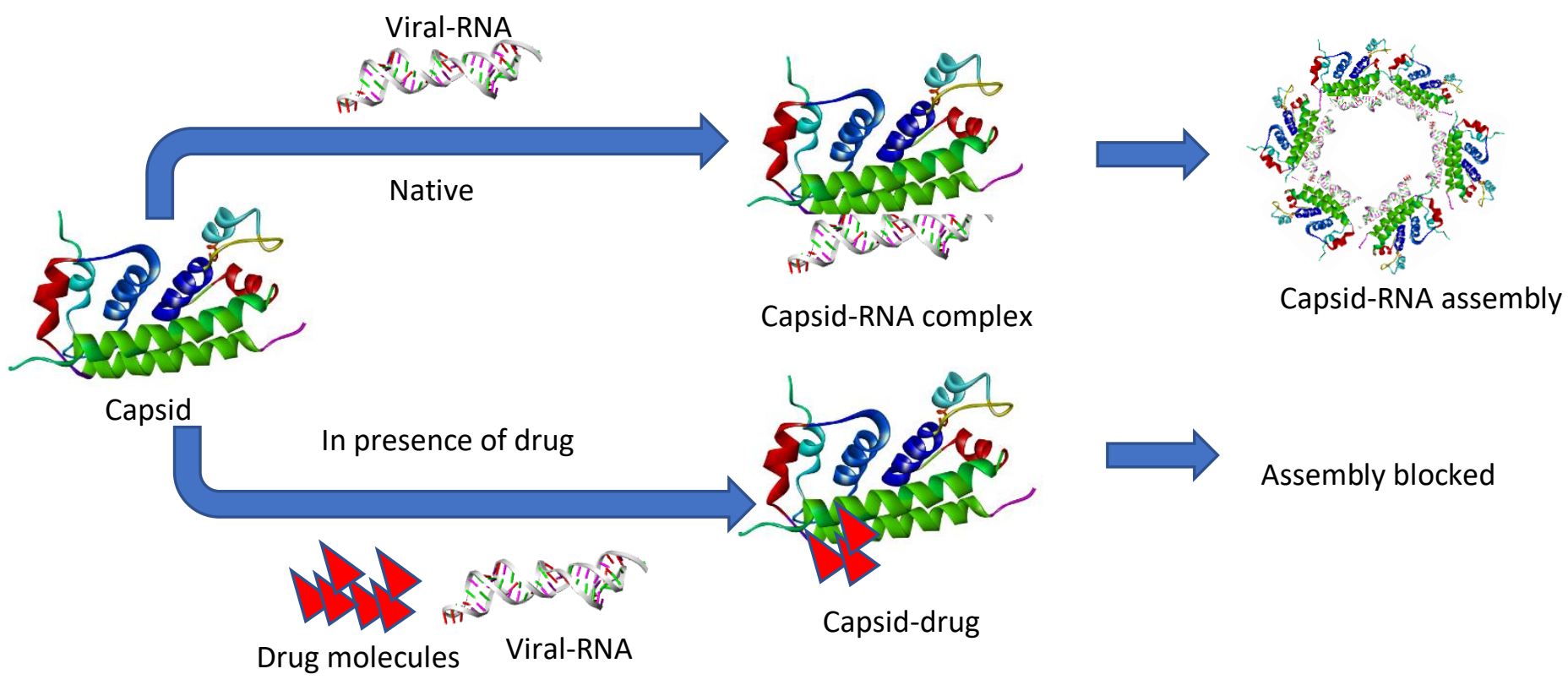

Figure 7: Schematic diagram capsid interaction. In native condition viral RNA binds to helix $\alpha 4$ (green) and assemble as to mature virion. In presence of drug molecules binding site is occupied by drug and RNA-capsid interaction is blocked. 
Table 2: Interacting amino acids of shortlisted drugs

\begin{tabular}{|c|c|c|c|c|c|}
\hline $\begin{array}{l}\text { Nature of } \\
\text { drug }\end{array}$ & Drug name & $\begin{array}{l}\text { Binding affinity } \\
\text { (Kcal/mol) }\end{array}$ & Types of bond & Interacting amino acids & $\begin{array}{l}\text { Bond length } \\
\text { (A) }\end{array}$ \\
\hline Anti-viral & Daclatasvir & -7.9 & $\begin{array}{l}\mathrm{H} \text {-bond } \\
\mathrm{C}-\mathrm{H} \text { bond } \\
\text { Pi-sigma } \\
\text { Pi-cation } \\
\text { Amide Pi-stacked } \\
\text { Pi-alkyl }\end{array}$ & $\begin{array}{l}\text { Asn } 93(B)(3) \\
\text { Arg } 98(A) \\
\text { Gly } 70(B) \\
\text { lle } 94(A) \\
\text { Arg } 90(A) \\
\text { Arg97 (A) } \\
\text { Asn } 93(A) \\
\text { Lys } 86(A) \\
\text { Arg } 90(A)(3) \\
\text { Leu } 66(B)\end{array}$ & $\begin{array}{l}2.5,2.4,2.4 \\
2.5 \\
3.4 \\
3.6 \\
4.8 \\
4.2 \\
5.0 \\
5.3 \\
4.5,4.2,4.9 \\
5.0 \\
\end{array}$ \\
\hline Anti-viral & Rilpivirin & -7.5 & $\begin{array}{l}\text { C-H bond } \\
\text { Pi-sigma } \\
\text { Pi-Pi T shaped } \\
\text { Pi-alkyl }\end{array}$ & $\begin{array}{l}\text { Gly } 70(A) \\
\text { Ile } 94(B) \\
\text { Leu } 66(A) \\
\text { Trp } 69(A)(2) \\
\text { Arg } 55(A) \\
\text { Pro } 61(A)(2) \\
\text { Leu } 66(A)\end{array}$ & $\begin{array}{l}3.4 \\
3.5 \\
5.2 \\
5.6,5.5 \\
5.2 \\
5.3,4.2 \\
5.2 \\
\end{array}$ \\
\hline Anti-viral & Tipranavir & -7.0 & $\begin{array}{l}\text { H-bond } \\
\text { Pi-sigma } \\
\text { Pi-alkyl }\end{array}$ & $\begin{array}{l}\text { Arg } 97(B)(2) \\
\text { Arg } 90(B) \\
\text { Ile } 94(B) \\
\text { Ile } 59(A) \\
\text { Pro } 61(\mathrm{~A})(2) \\
\text { Arg } 55(A) \\
\text { Ile } 94(B)\end{array}$ & $\begin{array}{l}2.2,2.2 \\
2.8 \\
\\
3.5 \\
\\
4.0 \\
4.7,4.1 \\
5.2 \\
4.9 \\
\end{array}$ \\
\hline $\begin{array}{l}\text { Anti- } \\
\text { microbial }\end{array}$ & Praziquantel & -7.3 & $\begin{array}{l}\text { Pi-sigma } \\
\text { Pi-alkyl }\end{array}$ & $\begin{array}{l}\text { Ile } 94(A) \\
\text { Leu } 66(B) \\
\text { Pro } 61(B)(3) \\
\text { Arg } 55(B)(2) \\
\text { lle } 94(A)\end{array}$ & $\begin{array}{l}3.9 \\
4.2 \\
4.4,4.3,5.1 \\
5.2,5.3 \\
4.3 \\
\end{array}$ \\
\hline $\begin{array}{l}\text { Anti- } \\
\text { microbial }\end{array}$ & Rifampicin & -6.9 & $\begin{array}{l}\text { H-bond } \\
\text { C-H bond } \\
\text { Pi-sigma }\end{array}$ & $\begin{array}{l}\text { Arg } 55(A)(2) \\
\text { Glu } 87(B) \\
\text { Lys } 45(B) \\
\text { Glu } 87(B) \\
\text { Ile } 59(A)(2)\end{array}$ & $\begin{array}{l}2.3,2.8 \\
2.9 \\
2.3 \\
3.2 \\
3.5,3.5 \\
\end{array}$ \\
\hline
\end{tabular}




\section{Acknowledgements}

We thank CSIR and AcSIR for academic support. Science and Engineering Research Board (SERB) is acknowledged for its support via SERB Early career research award and SERB woman excellence award to UR. Department of Biotechnology (DBT) is acknowledged for Ramalingaswamy fellowship award to UR.

\section{References:}

1. World Health Organisation (2020). Dengue and Severe Dengue [Fact Sheet]. Retrieved from https://www.who.int/news-room/fact-sheets/detail/dengue-and-severedengue\#: :text=The\%20global\%20incidence\%20of\%20dengue,400\%20million\%20inf ections\%20each\%20year.

2. Ma, L., Jones, C. T., Groesch, T. D., Kuhn, R. J., \& Post, C. B. (2004). Solution structure of dengue virus capsid protein reveals another fold. Proceedings of the National Academy of Sciences of the United States of America, 101(10), 3414-3419.

3. Markoff, L., Falgout, B., \& Chang, A. (1997). A conserved internal hydrophobic domain mediates the stable membrane integration of the dengue virus capsid protein. Virology, 233(1), 105-117.

4. Nemésio, H., Palomares-Jerez, M. F., \& Villalaín, J. (2013). Hydrophobic segment of dengue virus $C$ protein. Interaction with model membranes. Molecular membrane biology, 30(4), 273-287.

5. Teoh, P. G., Huang, Z. S., Pong, W. L., Chen, P. C., \& Wu, H. N. (2014). Maintenance of dimer conformation by the dengue virus core protein $\alpha 4-\alpha 4$ ' helix pair is critical for nucleocapsid formation and virus production. Journal of virology, 88(14), 7998-8015.

6. Limjindaporn, T., Netsawang, J., Noisakran, S., Thiemmeca, S., Wongwiwat, W., Sudsaward, S., Avirutnan, P., Puttikhunt, C., Kasinrerk, W., Sriburi, R., Sittisombut, N., Yenchitsomanus, P. T., \& Malasit, P. (2007). Sensitization to Fas-mediated apoptosis by dengue virus capsid protein. Biochemical and biophysical research communications, 362(2), 334-339.

7. Colpitts, T. M., Barthel, S., Wang, P., \& Fikrig, E. (2011). Dengue virus capsid protein binds core histones and inhibits nucleosome formation in human liver cells. PloS one, 6(9), e24365.

8. Mukherjee, D., Ray, U. (2020): SARS-CoV-2 Nucleocapsid Assembly Inhibitors: Repurposing Antiviral and Antimicrobial Drugs Targeting Nucleocapsid-RNA Interaction. ChemRxiv. Preprint.

9. Berman, H.M., Henrick, K., Nakamura, H. (2003). Announcing the worldwide Protein Data Bank. Nature Structural Biology 10 (12): 980.

10. [http://mgltools.scripps.edu/downloads]

11. Wishart, D.S., Knox, C., Guo, A.C., Shrivastava, S., Hassanali, M., Stothard, P., Chang, Z., Woolsey, J. (2006). Drugbank: a comprehensive resource for in silico drug discovery and exploration. Nucleic Acids Research. (Database issue): D668-72. 16381955. 
12. Trott, O., Olson, A.J. (2010). AutoDock Vina: improving the speed and accuracy of docking with a new scoring function, efficient optimization and multithreading, Journal of Computational Chemistry 31: 455-461

13. Dassault Systèmes BIOVIA, Discovery Studio Modelling Environment, Release 2017, San Diego: Dassault Systèmes, 2016.

14. DeLano, W. L. (2002). PyMOL. DeLano Scientific, San Carlos, CA, 700.

15. Guedj, J., Dahari, H., Rong, L., Sansone, N. D., Nettles, R. E., Cotler, S. J., Layden, T. J., Uprichard, S. L., \& Perelson, A. S. (2013). Modeling shows that the NS5A inhibitor daclatasvir has two modes of action and yields a shorter estimate of the hepatitis $C$ virus half-life. Proceedings of the National Academy of Sciences of the United States of America, 110(10), 3991-3996.

16. Goldner, T., Hewlett, G., Ettischer, N., Ruebsamen-Schaeff, H., Zimmermann, H., \& Lischka, P. (2011). The novel anticytomegalovirus compound AIC246 (Letermovir) inhibits human cytomegalovirus replication through a specific antiviral mechanism that involves the viral terminase. Journal of virology, 85(20), 10884-10893.

17. White, R. J., Lancini, G. C., \& Silvestri, L. G. (1971). Mechanism of action of rifampin on Mycobacterium smegmatis. Journal of bacteriology, 108(2), 737-741.

18. Faustino, A. F., Martins, A. S., Karguth, N., Artilheiro, V., Enguita, F. J., Ricardo, J. C., Santos, N. C., \& Martins, I. C. (2019). Structural and Functional Properties of the Capsid Protein of Dengue and Related Flavivirus. International journal of molecular sciences, 20(16), 3870. 